\title{
OPTIMIZATION OF COMPATIBLE SOLUTES FOR IMPROVING SURVIVAL OF FREEZE-DRIED LACTOBACILLUS DELBRUECKII SUBSP. BULGARICUS USING BOX-BEHNKEN DESIGN
}

\author{
- Short communication - \\ Guowei SHU ${ }^{1, *}$, Bohao $\mathrm{LI}^{1}$, Meng ZHANG ${ }^{2}$, Jie HUANG ${ }^{1}, \mathrm{Li}_{\mathrm{CHEN}}^{2}, \mathrm{Xu} \mathrm{DONG}^{3}$ \\ ${ }^{I}$ School of Food and Biological Engineering, Shaanxi University of Science and Technology, Xi'an, 710021, \\ China; \\ ${ }^{2}$ College of Food Engineering and Nutritional Science, Shaanxi Normal University, Xi'an 710119, P. R. \\ China. \\ ${ }^{3}$ Department of Research and Development, Shaanxi Yatai Dairy Co., Ltd., Xianyang, 713701, China
}

\begin{abstract}
Lactobacillus delbrueckii subsp. bulgaricus is widely used in yogurt as a starter. The freeze-drying process may cause bacteria death. In the present work, the effect of three solutes ( $\mathrm{NaCl}$, sorbitol, and sodium glutamate) in MRS on viability of L.bulgaricus during freeze-drying was investigated. The optimal combination of adequate solutes was chosen by Box-Behnken Design. The survival rate and viable counts in freeze-dried powder, as well as the viable counts in broth, were used as responses. The results revealed that the optimum combination of solutes in MRS broth were $0.50 \%$ $\mathrm{NaCl}, 0.19 \%$ sorbitol, and $0.06 \%$ sodium glutamate. Under these optimal conditions, the survival rate was $53.2 \pm 0.14 \%$, the viable counts in freeze-dried powder was $8.51 \pm 0.23 \times 10^{10} \mathrm{CFU} / \mathrm{g}$, and the viable counts in broth was $6.05 \pm 0.19 \times 10^{8}$ $\mathrm{CFU} / \mathrm{mL}$, which were increased by $17.18 \%, 15.94 \%$, and $17.31 \%$, respectively, compared to the control. This research demonstrated the possibility of viability improvement of L.bulgaricus, which may provide a feasible reference for industrial development.
\end{abstract}

Keywords: Lactobacillus bulgaricus; compatible solutes; freeze-drying; response surface methodology

\section{INTRODUCTION}

L.bulgaricus is one of the widely applicable lactic acid bacteria (LAB) strains that is extensively used as a starter for the manufacture of a variety of fermented dairy products (Chen et al., 2015). The industrial development of yogurt starters needs to ensure that they provide viable and functional cultures for a long time. Freeze-drying is recognized as a suitable drying technique to preserve yogurt starters. However, this process may cause cell death and loss of fermentation function (Chen et al., 2015). L.bulgaricus is indeed sensitive to freezedrying, which up to now can only be stabilized by freezing on an industrial scale. Finding ways to improve the survival of L.bulgaricus during freezedrying is of great interest. Some research found that sorbitol and sodium glutamate have a positive effect on cell survival (Carvalho et al., 2003a; Carvalho et al., 2010; Santivarangkna et al., 2010). Besides, it has been suggested that the addition of $\mathrm{NaCl}$ to the growth medium, as well as certain components as

Received: 02.10.2021

Accepted in revised form: 12.12.2021 sources of compatible solutes, lead to an increase in the accumulation of compatible solutes, and therefore promote survival of LAB during storage in the powder (Carvalho et al., 2003b). There is clear evidence that an adequate increase of osmotic pressure of the medium by adding $\mathrm{NaCl}$ to the MRS broth has improved the survival of freeze-dried L.bulgaricus during storage (Carvalho et al., 2010). However, the intracellular accumulation and protection of compatible solutes in each lactic acid bacteria strain may be different under osmotic stress (Obis et al., 2010; Le et al., 2007). Thus, mechanisms of adaptation involving the accumulation of compatible solutes in each LAB strains are the current research focuses (Johannes et al., 2021).

In our work, the Plackett-Burman design was revealed that sorbitol, sodium glutamate, and $\mathrm{NaCl}$ in MRS medium could affect significantly the survival rate of L.bulgaricus during freeze-drying and demonstrated highly significant effects (Chen et al., 2017). In this study, Box-Behnken design (BBD) was adopted to further optimize the combination of the three solutes in MRS medium.

*Corresponding author. E-Mail address: shuguowei@gmail.com 


\section{MATERIALS AND METHODS}

\section{Microorganism and media}

L.bulgaricus was obtained from the School of Food and Biological Engineering (Shaanxi University of Science \& Technology) which was screened from Inner Mongolia traditional yogurt. The MRS broth and MRS agar medium were purchased from Shandong Tuopu Biological Engineering Co., Ltd. (Zhaoyuan City, China).

\section{Preparation of antifreeze agent and freeze-dried L.bulgaricus}

The impact of the main factors has been studied by Plackett-Burman design in previous research (Chen et al., 2017). Consequently, $\mathrm{NaCl}$ (Tian in Fuyu Fine Chemical Co., Ltd., Tianjin, China), sorbitol (Shanghai Shan Pu Chemical Co., Ltd., Shanghai, China), and sodium glutamate (Xi'an Rosen Biotech Co., Ltd., Xi'an, China) were selected as the best freeze-drying antifreeze agents for L.bulgaricus. $\mathrm{NaCl}$, sorbitol, and sodium glutamate were formulated into various concentrations with distilled water and added into MRS broth. After sterilization at $121^{\circ} \mathrm{C}$ for $15 \mathrm{~min}$, the L.bulgaricus was continuously activated for three generations, which inoculated at a level of $2 \%(\mathrm{v} / \mathrm{v})$ into MRS medium, and then the medium was stored at $37^{\circ} \mathrm{C}$ for $22 \mathrm{~h}$. The sediments of L.bulgaricus culture were centrifuged $(8000 \mathrm{r} / \mathrm{min}, 15$ minutes $)$ at $25^{\circ} \mathrm{C}$ (Model GL21, Instrumentation, Hunan), washed with saline, and centrifuged. The procedure was repeated twice then an equal volume of phosphate buffer was added and prefrozen under $-80^{\circ} \mathrm{C}$ for 4 $\mathrm{h}$ and then frozen using a vacuum freeze dryer $(-50$ ${ }^{\circ} \mathrm{C}, 6.95 \mathrm{~Pa}$ for $24 \mathrm{~h}$ ).

Survival rate $(\%)=\frac{\text { Viable counts after freeze }- \text { drying }(\mathrm{CFU} / \mathrm{mL})}{\text { Viable counts before freeze }- \text { drying }(\mathrm{CFU} / \mathrm{mL})} \times 100$

\section{RESULTS AND DISCUSSION}

\section{Experimental results of Box-Behnken design}

The results of the experimental design using BBD

for antifreeze agents of L.bulgaricus are shown in Table 2.

Table 2. Experimental results of Box-Behnken design for antifreeze factor of L.bulgaricus

\begin{tabular}{ccccccc}
\hline Runs & $\mathrm{X}_{1}(\%)$ & $\mathrm{X}_{2}(\%)$ & $\mathrm{X}_{3}(\%)$ & $\mathrm{Y}_{1}(\%)$ & $\mathrm{Y}_{2}\left(\times 10^{10} \mathrm{CFU} / \mathrm{g}\right)$ & $\mathrm{Y}_{3}\left(\times 10^{8} \mathrm{CFU} / \mathrm{mL}\right)$ \\
\hline 1 & $-1(0.40)$ & $-1(0.17)$ & $0(0.06)$ & 32.6 & 5.3 & 5.30 \\
2 & -1 & $1(0.21)$ & 0 & 29.3 & 5.1 & 5.19 \\
3 & $1(0.60)$ & -1 & 0 & 33.5 & 5.4 & 5.17 \\
4 & 1 & 1 & 0 & 28.9 & 4.1 & 5.25 \\
5 & $0(0.50)$ & -1 & $-1(0.04)$ & 35.4 & 5.1 & 5.75 \\
6 & 0 & -1 & $1(0.08)$ & 31.2 & 5.6 & 5.77 \\
7 & 0 & 1 & -1 & 30.1 & 4.7 & 5.81 \\
8 & 0 & 1 & 1 & 32.3 & 5.3 & 5.87 \\
9 & -1 & $0(0.19)$ & -1 & 32.5 & 5.4 & 5.32 \\
\hline
\end{tabular}

\section{Determination of Cell Counts}

The number of L.bulgaricus was determined before and after freeze-drying. The freeze-dried powder of L.bulgaricus was added to sterile saline for serial dilution. Later, a sterile syringe has been used to plate and spread the evenly, then keep the plate at $37^{\circ} \mathrm{C}$ for $72 \mathrm{~h}$. The viability of L. bulgaricus was detected by the standard counting method on MRS agar. The survival rate calculation method is those given in eq. (1).

\section{Optimization of antifreeze agents by Box- Behnken design (BBD)} Table 1). In order to evaluate the fitness of the data,

Table 1. Factor levels coding of Box-Behnken for antifreeze agents of L.bulgaricus

\begin{tabular}{lccc}
\hline \multirow{2}{*}{ Factors } & \multicolumn{3}{c}{ Coded Levels } \\
\cline { 2 - 4 } $\mathrm{NaCl}(\%)$ & -1 & 0 & 1 \\
Sorbitol (\%) & 0.40 & 0.50 & 0.60 \\
Sodium glutamate (\%) & 0.17 & 0.19 & 0.21 \\
\hline
\end{tabular}

\section{Statistical analysis of the data}

Design Expert (Version 8.0.6, Stat-Ease. Inc) used to perform variance analysis on the obtained experimental data, establish quadratic regression equations and three-dimensional response surface plots. 


\begin{tabular}{lclllll}
\hline 10 & 1 & 0 & -1 & 44.3 & 6.3 & 5.58 \\
11 & -1 & 0 & 1 & 35.8 & 6.7 & 5.47 \\
12 & 1 & 0 & 1 & 33.5 & 5.1 & 5.41 \\
13 & 0 & 0 & 0 & 53.2 & 8.7 & 6.18 \\
14 & 0 & 0 & 0 & 58.3 & 8.4 & 6.20 \\
15 & 0 & 0 & 0 & 52.1 & 8.6 & 6.13 \\
\hline
\end{tabular}

The survival rate, the viable counts in freeze-dried powder, and the viable counts in broth were represented by $\mathrm{Y}_{1}(\%)$, $\mathrm{Y}_{2}\left(\times 10^{10} \mathrm{CFU} / \mathrm{g}\right)$, and $\mathrm{Y}_{3}\left(\times 10^{8} \mathrm{CFU} / \mathrm{mL}\right)$, respectively.

\section{Regression analysis and analysis of variance}

The developed quadratic equations were obtained by using Design Export as follows:

$$
\begin{aligned}
& Y_{1}=54.53+1.25 \mathrm{X}_{1}-1.51 \mathrm{X}_{2}-1.19 \mathrm{X}_{3}-0.32 \mathrm{X}_{1} \mathrm{X}_{2}-3.52 \mathrm{X}_{1} \mathrm{X}_{3}+1.60 \mathrm{X}_{2} \mathrm{X}_{3}-9.59 \mathrm{X}_{1}^{2}-13.87 \mathrm{X}_{2}^{2}-8.42 \mathrm{X}_{3}^{2} \\
& \mathrm{Y}_{2}=8.57-0.20 \mathrm{X}_{1}-0.28 \mathrm{X}_{2}+0.15 \mathrm{X}_{3}-0.27 \mathrm{X}_{1} \mathrm{X}_{2}-0.63 \mathrm{X}_{1} \mathrm{X}_{3}+0.025 \mathrm{X}_{2} \mathrm{X}_{3}-1.45 \mathrm{X}_{1}^{2}-2.15 \mathrm{X}_{2}^{2}-1.25 \mathrm{X}_{3}^{2} \\
& Y_{3}=6.17+0.016 X_{1}+0.016 X_{2}+0.0075 X_{3}+0.047 X_{1} X_{2}-0.08 X_{1} X_{3}+0.01 X_{2} X_{3}-0.65 X_{1}^{2}-0.29 X_{2}^{2}
\end{aligned}
$$

where $\mathrm{Y}_{1}, \mathrm{Y}_{2}$, and $\mathrm{Y}_{3}$ correspond to predicted value of survival rate, the viable counts in freeze-dried powder, and the viable counts in broth of L.bulgaricus, respectively. $\mathrm{X}_{1}, \mathrm{X}_{2}$, and $\mathrm{X}_{3}$ are the real values of the independent variables, $\mathrm{NaCl}$, sorbitol, and sodium glutamate, respectively.

Analysis of variance results summarized in Table 3 indicated that the regression models were very significant $(\mathrm{p}<0.01)$. The quadratic terms of all regression equations except $\mathrm{X}_{3}{ }^{2}$ of $\mathrm{Y}_{3}$ were smaller than 0.05 , which suggested $\mathrm{X}_{1}^{2}, \mathrm{X}_{2}^{2}$, and $\mathrm{X}_{3}^{2}$ have a significant impact on the response value. The $\mathrm{p}$ value of the interaction coefficient X1X3 was smaller than 0.05 , which indicated the significant interaction between $\mathrm{NaCl}$ and sodium glutamate. However, the interactions between $\mathrm{NaCl}$ and sorbitol, sorbitol, and sodium glutamate were not significant $(\mathrm{p}>0.05)$. The $\mathrm{R}_{\text {adj }}^{2}$ value for $\mathrm{Y}_{1}$ of 0.9186 was close to the $\mathrm{R}^{2}$ meaning that the model was significant. Besides, $\mathrm{R}_{\text {adj }}$ values for $\mathrm{Y}_{2}$ and $\mathrm{Y}_{3}$ were close to $\mathrm{R}^{2}$ indicating that the developed models were highly significant with a good relationship between predicted and measured values of viable counts in both freeze-dried powder $\left(\mathrm{Y}_{2}\right)$ and viable counts in broth $\left(\mathrm{Y}_{3}\right)$.

\section{Response surface plot analysis}

Design-Expert was applied to analyze the regression equation, and 3D plots conception (Figures 1-3). These response surface plots could explain the influence of independent variables and their interactions. When the addition of $\mathrm{NaCl}$ was $0.50 \%$, the concentration of sorbitol was $0.19 \%$, and the concentration of sodium glutamate was $0.06 \%$, the values of survival rate $(54.54 \%)$, the viable counts in freeze-dried powder $\left(8.57 \times 10^{10} \mathrm{CFU} . \mathrm{g}^{-1}\right)$, and viable counts in broth $\left(6.17 \times 10^{8}\right.$ CFU.mL $\left.{ }^{-1}\right)$ of L.bulgaricus were obtained respectively, which

\begin{tabular}{|c|c|c|c|c|c|c|c|}
\hline \multirow{2}{*}{ Source } & \multicolumn{3}{|c|}{$\mathrm{Y}_{1}$} & \multicolumn{2}{|c|}{$Y_{2}$} & \multicolumn{2}{|c|}{$Y_{3}$} \\
\hline & $\mathrm{DF}^{\mathrm{a}}$ & $\mathrm{MS}^{\mathrm{b}}$ & $p$-value ${ }^{c}$ & $\mathrm{MS}^{\mathrm{b}}$ & $p$-value ${ }^{\mathrm{c}}$ & $\mathrm{MS}^{\mathrm{b}}$ & $p$-value ${ }^{\mathrm{c}}$ \\
\hline model & 9 & 139.11 & 0.0025 & 3.30 & 0.0001 & 0.20 & 0.0002 \\
\hline $\mathrm{X}_{1}$ & 1 & 12.50 & 0.2532 & 0.32 & 0.0547 & 0.0021 & 0.4721 \\
\hline $\mathrm{X}_{2}$ & 1 & 18.30 & 0.1790 & 0.61 & 0.0186 & 0.0021 & 0.4721 \\
\hline $\mathrm{X}_{3}$ & 1 & 11.28 & 0.2747 & 0.18 & 0.1200 & 0.0004 & 0.7344 \\
\hline $\mathrm{X}_{1} \mathrm{X}_{2}$ & 1 & 0.42 & 0.8218 & 0.30 & 0.0596 & 0.0090 & 0.1690 \\
\hline $\mathrm{X}_{1} \mathrm{X}_{3}$ & 1 & 49.70 & 0.0498 & 1.56 & 0.0027 & 0.026 & 0.0425 \\
\hline$X_{2} X_{3}$ & 1 & 10.24 & 0.2953 & 0.0025 & 0.8341 & 0.0004 & 0.7489 \\
\hline $\mathrm{X}_{1}{ }^{2}$ & 1 & 339.69 & 0.0011 & 7.72 & $<0.0001$ & 1.55 & $<0.0001$ \\
\hline $\mathrm{X}_{2}{ }^{2}$ & 1 & 709.97 & 0.0002 & 17.00 & $<0.0001$ & 0.32 & 0.0002 \\
\hline $\mathrm{X}_{3}{ }^{2}$ & 1 & 261.56 & 0.0020 & 5.73 & 0.0001 & 0.021 & 0.0560 \\
\hline Residual & 5 & 7.50 & & 0.051 & & 0.0035 & \\
\hline Lack of fit & 3 & 5.21 & 0.7313 & 0.070 & 0.2599 & 0.0049 & 0.2147 \\
\hline Pure error & 2 & 10.94 & & 0.023 & & 0.0013 & \\
\hline $\mathrm{R}^{2}$ & & & 0.9709 & & 0.9914 & & 0.9905 \\
\hline $\mathrm{R}^{2}{ }_{\text {adj }}$ & & & 0.9186 & & 0.9760 & & 0.9733 \\
\hline
\end{tabular}
reached the maximum responses.

Table 3. Experimental results of Box-Behnken design for antifreeze factor of L.bulgaricus

${ }^{\mathrm{a}}$ Degrees of freedom; ${ }^{\mathrm{b}}$ Mean square; ${ }^{\mathrm{C}}$ The F-test probability values; the survival rate, the viable counts in freeze-dried powder, and the viable counts in broth were represented by $\mathrm{Y}_{1}(\%), \mathrm{Y}_{2}\left(\times 10^{10} \mathrm{CFU} / \mathrm{g}\right), \mathrm{Y}_{3}\left(\times 10^{8} \mathrm{CFU} / \mathrm{mL}\right)$, respectively.; $\mathrm{NaCl}$, sorbitol, and sodium glutamate were represented by $\mathrm{X} 1, \mathrm{X}_{2}$ and $\mathrm{X} 3$,respectively. 
The results of verification experiments, tested in triplicate, showed that the mean value of the survival rate, the viable counts in freeze-dried powder, and the viable counts in broth of L.bulgaricus were $53.2 \pm 0.14 \%, 8.51 \pm 0.23 \times 10^{10}$ CFU/g, and $6.05 \pm 0.19 \times 10^{8} \mathrm{CFU} / \mathrm{mL}$. These results were statistically similar to the predicted values. The control had values of the survival rate as $45.4 \%$,

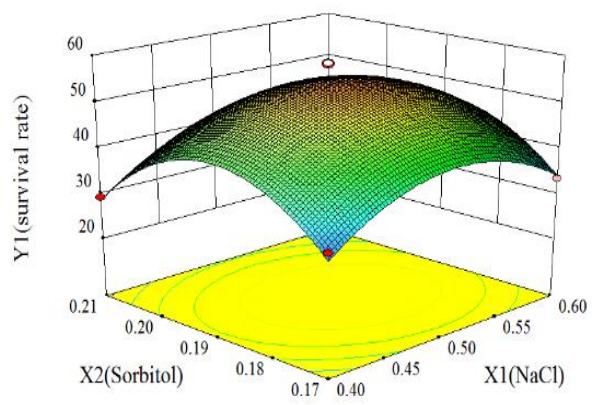

(a)

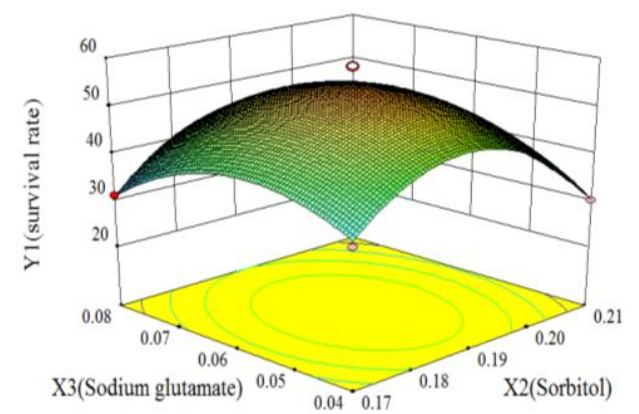

(c)

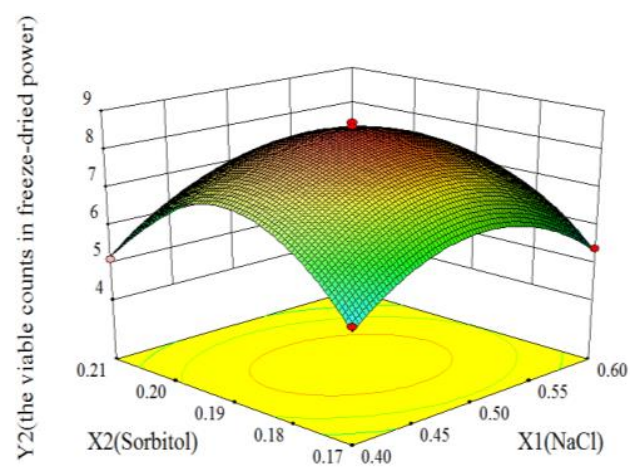

(a)

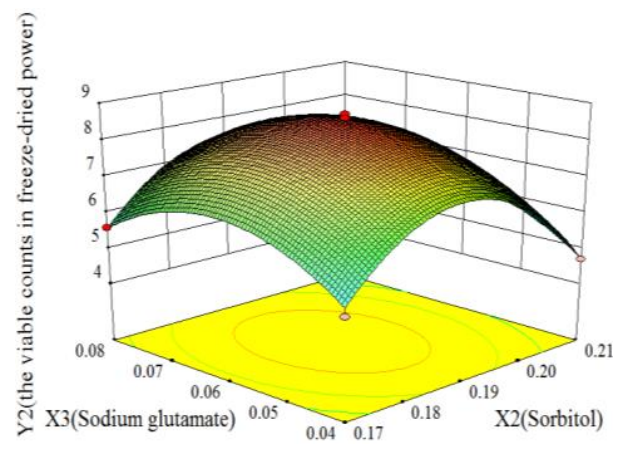

(c) the viable counts in freeze-dried powder as $5.2 \times 10^{10}$ $\mathrm{CFU} / \mathrm{g}$, and the viable counts in broth as $5.13 \times 10^{8}$ $\mathrm{CFU} / \mathrm{mL}$. Comparing the control and optimized mediums, the viable counts, the viable counts in freeze-dried powder, and the survival rate in broth were improved by $17.18 \%, 63.65 \%$, and $17.93 \%$, respectively.

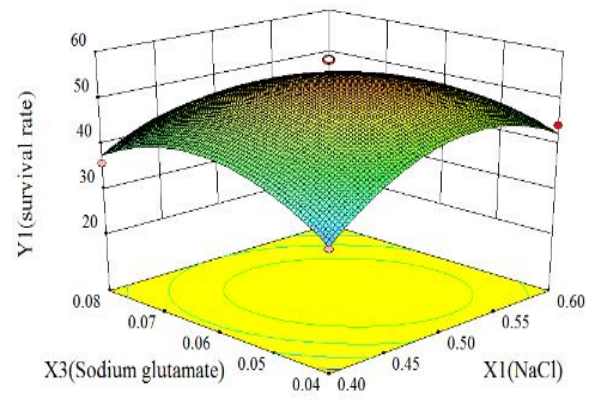

(b)

Figure 1. Response surface plots of survival rate showing interactions between (a) $\mathrm{NaCl}$ and sorbitol, (b) $\mathrm{NaCl}$ and sodium glutamate, (c) sorbitol and sodium glutamate

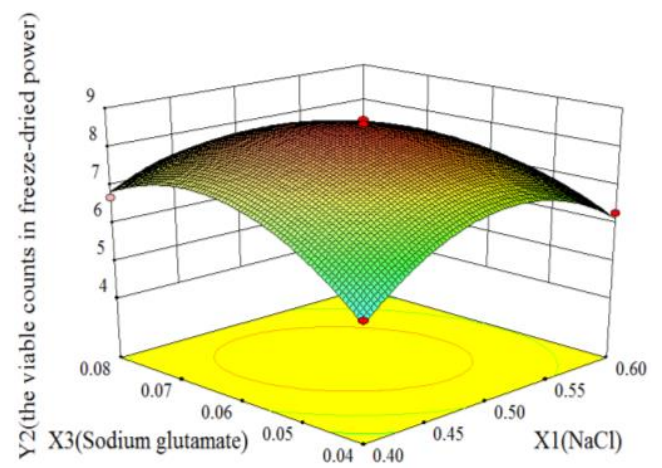

(b)

Figure 2. Response surface plots of the viable counts in freeze-dried powder showing interactions between (a) $\mathrm{NaCl}$ and sorbitol, (b) $\mathrm{NaCl}$ and sodium glutamate, (c) sorbitol and sodium glutamate 


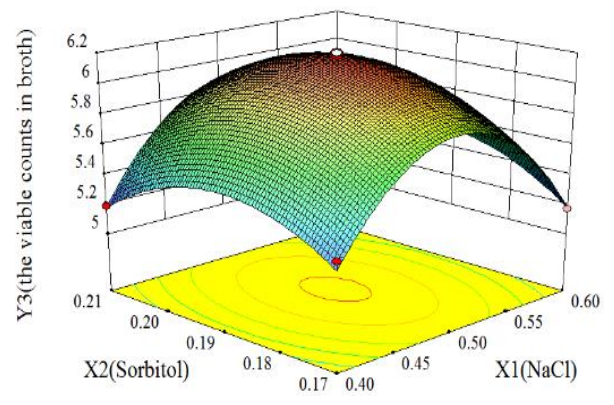

(a)

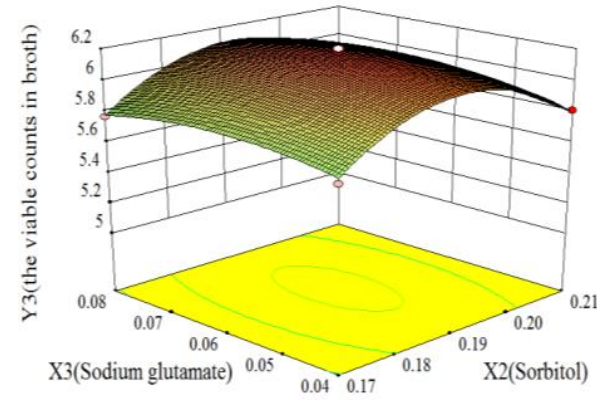

(c)

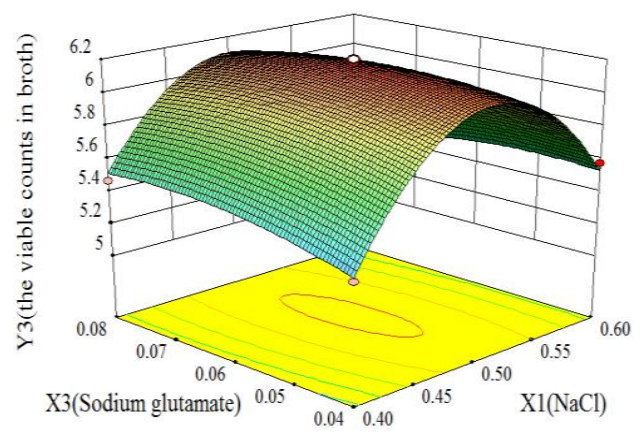

(b)

Figure 3. Response surface plots of the viable counts in broth showing interactions between (a) $\mathrm{NaCl}$ and sorbitol, (b) $\mathrm{NaCl}$ and sodium glutamate, (c) sorbitol and sodium glutamate

The activity of L.bulgaricus after freeze-drying was of great economic significance to the dairy industry, so there was a lot of research on how to improve its freeze-dried activity, and the measures taken include accumulation of compatible solutes such as betaine and carnitine (Kets \& de Bont, 1994; Kets et al., 1996), sub-lethal treatments (heat, cold, and acid shocks) (Broadbent and Lin, 1999, Silva et al., 2005) and optimization of freeze-drying protectants (Romano et al., 2016). However, research on the accumulation of compatible solutes in lactic acid bacteria to improve their freeze-drying survival rate and stability has received little attention and its mechanism of action is still unclear. Kets \& de Bont (1994) found that adding betaine in the presence of $0.6 \mathrm{M} \mathrm{NaCl}$ has a significant effect on the growth rate of Lactobacillus plantarum and can resist drying better than unstressed cells.

In this study, we optimized the best combination of $\mathrm{NaCl}$, sorbitol, and sodium glutamate using BBD and found $\mathrm{NaCl}$ and sodium glutamate have a significant interactive effect on improving the survival rate, the viable counts in freeze-dried powder, and the viable counts in broth. It was

\section{CONCLUSION}

The optimal combination of three compounds on improving survival of L.bulgaricus was $\mathrm{NaCl}$ of $0.50 \%$, sorbitol of $0.19 \%$, and sodium glutamate of $0.06 \%$. Under these conditions, the survival rate, the demonstrated that the addition of the optimal combination solutes to MRS broth increases significantly survival of $L$ bulgaricus.

In the process of continuous drying, when the moisture content decreases rapidly, the cells were prone to rupture due to the phase change in the drying or rehydration process. Therefore, the cell membrane was the key part of the loss of bacterial activity during the freeze-drying process. Besides, sorbitol can prevent lipid oxidation of cell membrane thus decreasing cell membrane damage. Relevant evidence shows the ability to stabilize protein structure and retain more residual water through the reaction between the amino group of protective agent and carboxyl group of microbial protein (de Valdéz et al., 1983), which was an explanation for the effect of sodium glutamate in the freeze-drying process. Our research showed that choosing a suitable protective agent as the additive of the drying medium was a necessary condition for the strong protection of lyophilized L. bulgaricus. The best combination of three substances added to the MRS broth can improve significantly viability of freeze-dried L.bulgaricus.

viable counts in freeze-dried powder, and the viable counts in broth of freeze-dried L.bulgaricus increased by $53.2 \%, 8.51 \times 10^{10} \mathrm{CFU} / \mathrm{g}$, and $6.05 \times 10^{8} \mathrm{CFU} / \mathrm{mL}$ compared to control, respectively. Our study provided a good reference for industrial exploitation of L.bulgaricus starters. 


\section{ACKNOWLEDGMENTS}

The work was partially supported by the National Key R\&D Program-Technology Boosts Economy 2020 Key Special Project, the Key Research and Development Program of Shaanxi (Program No. 2019ZDLNY06-02 and $2020 \mathrm{KW}-031)$.

\section{REFERENCES}

1. Abadias, M., Benabarre, A., N Teixidó, Usall, J., \& ViAs, I. (2001). Effect of freeze drying and protectants on viability of the biocontrol yeast candida sake. International Journal of Food Microbiology, 65(3), 173182. Doi:10.1016/s0168-1605(00)00513-4.

2. Broadbent, J., \& Lin, C. (1999). Effect of heat shock or cold shock treatment on the resistance of Lactococcus lactis to freezing and lyophilization. Cryobiology, 39, 88-102. DOI: 10.1006/cryo.1999.2190.

3. Carvalho, A., Silva, J., Ho, P., Teixeira, P., Malcata, F. X., \& Gibbs, P. (2003a). Protective effect of sorbitol and monosodium glutamate during storage of freeze-dried lactic acid bacteria. Dairy Science \& Technology, 83(3), 203-210. Doi:10.1051/lait:2003010.

4. Carvalho, A. S., Silva, J., Ho, P., Teixeira, P., Malcata, F. X., \& Gibbs, P. (2003b). Effect of various factors upon thermotolerance and survival during storage of freeze-dried Lactobacillus delbrueckii ssp. bulgaricus. Journal of Food Science, 68(8), 2538-2541.

5. Chen, H., Chen, S., Li, C., \& Shu, G. (2015). Response surface optimization of lyoprotectant for lactobacillus bulgaricus during vacuum freeze-drying. Preparative Biochemistry and Biotechnology, 45(5), 463-475. Doi:10.1080/10826068.2014.923451.

6. Chen, H. Huang, J. Shi, X. Y., Li, Y., \& Liu, Y. (2017). Effects of six substances on the growth and freeze-drying of Lactobacillus delbrueckii subsp.bulgaricus. Acta Scientiarum Polonorum Technologia Alimentaria, 16, 403-412. Doi:10.17306/j.afs.0512.

7. de Valdéz, G. F., de Giori, G. S., Aa, D. R. H., \& Oliver, G. (1983). Protective effect of adonitol on lactic acid bacteria subjected to freeze-drying. Applied \& Environmental Microbiology, 45(1), 302-4. Doi:10.1128/aem.45.1.302-304.1983.

8. Johannes F. I.,Tanja Rahn,Sven Künzel,Alexander Keller \& Sven C. Neulinger. (2021). Osmotic Adaptation and Compatible Solute Biosynthesis of Phototrophic Bacteria as Revealed from Genome Analyses. Microorganisms, 9(1), 46. https://doi.org/10.3390/microorganisms9010046.

9. Kets, E., \& de Bont, J. (1994). Protective effect of betaine on survival of Lactobacillus plantarum subjected to drying. FEMS Microbiology Letters, 116, 251-256. Doi: 10.1111/j.15746968.1994.tb06711.x.

10. Kets, E., Teunissen, P., \& de Bont, J. (1996). Effect of compatible solutes on survival of lactic acid bacteria subjected to drying. Applied and Environmental Microbiology, 62(1), 259-261.

11. Le, M. C., Bon, E., \& Lonvaudfunel, A. (2007). Tolerance to high osmolality of the lactic acid bacterium oenococcus oeni and identification of potential osmoprotectants. International Journal of Food Microbiology, 115(3), 335-342. Doi:10.1016/j.ijfoodmicro.2006.12.039.

12. Obis, D., Guillot, A., \& Mistou, M. Y. (2010). Tolerance to high osmolality of Lactococcus lactis subsp. lactis and cremoris is related to the activity of a betaine transport system. Fems Microbiology Letters, 202(1), 39-44. Doi:10.1111/j.1574-6968.2001.tb10777.x.

13. Pehkonen, K. S., Roos, Y. H., Miao, S., Ross, R. P., \& Stanton, C. (2008). State transitions and physicochemical aspects of cryoprotection and stabilization in freeze-drying of lactobacillus rhamnosus GG (LGG). Journal of Applied Microbiology, 104(6), 1732-1743. Doi:10.1111/j.13652672.2007.03719.x.

14. Romano N., Schebor C., Mobili P., Gómez-Zavaglia A. (2016). Role of mono- and oligosaccharides from FOS as stabilizing agents during freeze-drying and storage of Lactobacillus delbrueckii subsp. Bulgaricus. Food Research International, 90:251-258. doi: 10.1016/j.foodres.2016.11.003.

15. Santivarangkna, C., Naumann, D., Kulozik, U., \& Foerst, P. (2010). Protective effects of sorbitol during the vacuum drying of lactobacillus helveticus: an ft-ir study. Annals of Microbiology, 60(2), 235-242. Doi:10.1007/s13213-010-0032-5.

16. Silva, J., Carvalho, A., Domingues, P., Ferreira, R., Vitorino, R.,Teixeira, P., \& Gibbs, P. A. (2005). Effect of the $\mathrm{pH}$ of growth on the resistance of Lactobacillus delbrueckii spp. Bulgaricus to stress conditions. Applied and Environmental Microbiology, 98(3):775-782. Doi:10.1111/j.13652672.2004.02516.x. 